[Agr. Biol. Chem., Vol. 30, No. 12, p. 1221 1232, 1966]

\title{
The Influence of Measurement Parameters on the Specific Rotation of Amino Acids
}

\section{Part I. The Effect of Solute and Hydrochloric Acid Concentration on Optical Rotation*}

\author{
By Koichi HaYashi, Yutaka FujII, Ryuichi SAIto, \\ Hiroyuki KANAO and Tetsuo Hino \\ Kawasaki Factory, Ajinomoto Co., Inc. \\ Kawasaki, Japan \\ Received June 6, 1966
}

\begin{abstract}
The effects of solute and hydrochloric acid concentrations on optical rotation were studied using 20 naturally occuring amino acids.

There appeared to be no common factor among the amino acids as far as the inclination of optical rotation was concerned. Lutz-Jirgenson's rule could be applied to few amino acids in the cationic form. Therefore, in the determination of the optical rotation, the concentration of the solute, nature of solvent and temperature must be rigorously controlled. The optical conditions of measurement and the specific rotation of 20 amino acids were recommended based on this work.
\end{abstract}

\section{INTRODUCTION}

The optical rotation of amino acids has been measured for general purposes, namely (a) as an indication of the optical purity of an amino acid; (b) to specifically characterize a new amino acid in terms of a particular physical constant; and (c) with the assistance of a certain empirical optical rotatory relations to determine whether an amino acid is of $\mathrm{L}$ - or $\mathrm{D}$-configuration.

The optical rotation values generally given in literature have an empirical quality. As a rule, only a single rotation value of a given compound is described and that under quite arbitrarily selected conditions. The values are a function of the nature of the solvent, of the concentration of solute, of temperature, of wavelength of light source, and in many cases of the concentration of acid an alkali

* A part of this study was published at the Annual Meeting of the Agricultural Chemical Society of Japan in 1965. employed. Some references ${ }^{1 \sim 101}$ are available for optical rotation study, but not systematically. In the present experiment, effects on rotation caused by solute and solvent concentratoin using 20 naturally occurring amino acids are investigated.

\section{EXPERIMENTALS}

1) Amino Acids to be Tested. The purities of

1) R. L. Shriner, K. Adams, and C.S. Marvel, "Organic Chemistry" Vol, 1, John Wily and Sons, New York, P.214, (1942).

2) J.P. Greenstein, C. R. Birbaue, and M.C. Otey, J. Biol. Chem., 204, 307 (1953).

3) J.P. Greenstein, and M. Winitz, "Chemistry of the Amino Acids" Vol. 2, John Wiley and Sons., New York (1961).

4) O. Lutz, and Br. Jirgensons, Ber., 63, 448 (1930), 64, 1221 (1931).

5) T. Ogawa, J. Chem. Soc. Japan, (Nippon Kagaku Kaishi) 52, 69 (1948).

6) M.S. Denn, L. H. Frieden, M.P. Stodard, and H. V. Brown, J. Biol. Chem., 151, 241 (1943).

7) H. K. Miller, and J.C. Andrews, ibid., 87, 435 (1930)

8) M.S. Dunn, E.H. Frieden, M.D. Stodard, and H. V. Brown. ibid., 144, 495 (1942).

9) D. N. Thomas, and C. Nieman, ibid., 175, 241 (1948).

10) T. R. Spies, ibid., 182, 439 (1950). 


\section{TABLE I. EXPERIMENTAL CoNDITION}

\begin{tabular}{ll}
\multicolumn{1}{c}{ Amino Acids } & \multicolumn{1}{c}{$\begin{array}{c}\text { Solute } \\
\text { Concentration*1) }\end{array}$} \\
L-Alanine & $4,6,8,10,12$ \\
L-Arginine HCl & $2,4,6,8,12$ \\
L-Aspartic acid & $2,4,6,8,10$ \\
L-Gitrulline & $2,4,6,8,10$ \\
L-Cystine & $0.5,1,2,3$ \\
L-Glutamic acid & 10 \\
L-Glutamine & $1,2,3$ \\
L-Histidine HCl· $\mathrm{H}_{2} \mathrm{O}$ & $1,4,7,11,15$ \\
& $2,4,6,8,10$ \\
L-Hydroxyproline & $2,4,6,8,10$ \\
L-Isoleucine & $1,2,4,6,8$ \\
L-Leucine & $1,2,4,6,8$ \\
L-Lysin HCl & $2,4,6,8,12$ \\
L-Methionin & $2,4,6,8,10$ \\
L-Phenylalanine & $1,1.5,2,2.5$ \\
L-Proline & $2,4,6,8,10$ \\
L-Serine & $2,4,6,8,10$ \\
L-Threonine & $3,6,9,12$ \\
L-Tryptophan & $1,2,4,6,8$ \\
L-Tyrosine & $1,2,4,6,8$ \\
L-Valine & $0.2,0.5,1,1.5,2$ \\
*1) g/d1 & $0.5,1,2,5,7$ \\
*2) of optical rotation & $2,4,6,8,10$ \\
& \\
& \\
&
\end{tabular}

$\begin{array}{lc}\begin{array}{c}\text { Normality of } \\ \text { Hydrochloric acid }\end{array} & \begin{array}{c}\text { Temperature*2) } \\ \text { Coefficient }\end{array} \\ 1,2,4,5,6 & -0.07 \\ 2,3,4,5,6 & -0.03 \\ 1,2,3,4,5,6 & -0.09 \\ 1,2,4,5,6 & - \\ 1,2,3,4,5 & +2.0 \\ 0.6,1,1.5,2,3 & -0.07 \\ 1.3,0.5,0.7,1.0 & -0.07 \\ 1,2,4,5,6 & +0.14 \\ 1,2,4,6 & +0.10 \\ \left(\mathrm{H}_{2} \mathrm{O}\right) & -0.11 \\ 1,2,4,5,6 & +0.06 \\ 1,2,4,5,6 & -0.04 \\ 2,3,4,5,6 & +0.04 \\ 1,2,4,5,6 & +0.13 \\ \left(\mathrm{H}_{2} \mathrm{O}\right) & 0.00 \\ 1,2,4,6 & -0.09 \\ \left(\mathrm{H}_{2} \mathrm{O}\right) & +0.04 \\ 1,2,4,5,6 & +0.16 \\ 1,2,4,6 & +0.23 \\ \left(\mathrm{H}_{2} \mathrm{O}\right) & -0.06 \\ \left(\mathrm{H}_{2} \mathrm{O}\right) & \\ 1,2,3,4,5 & \\ 1,2,4,5,6 & \end{array}$

the amino acids used in this study are over $99.0 \%$. The amino acids are L-form and manufactured from protein hydrostates, by fermentation or synthesis, and purities are checked by paper chromatography, Damino acid oxidases and elementary analysis.

2) Measurement Condition. The measurements were carried out at $20^{\circ} \mathrm{C}$ under the following conditions (Table I). In the case the solution temperature is not at $20^{\circ} \mathrm{C}$, the specific rotation is calculated by the following formula:

$$
[\alpha]_{\mathrm{D}}^{20}=[\alpha]_{\mathrm{D}}^{t}+\alpha \times(20-t)
$$

where, $t=$ solution temperature $\left(15\right.$ to $\left.30^{\circ} \mathrm{C}\right)$

$a=$ temperature coefficient (See Table II).

3) The Polarimeter. Measurements were made in an Erma tube of $20 \mathrm{~cm}$ length using a sodium spectrum D-line with a Rudolph photoelectric precision polarimeter. The precision of measurement is within $\pm 0.01^{\circ}$.

\section{RESULTS AND DISCUSSIONS}

\section{On the Ionic Form of Amino Acids}

Concerning the optically active inoic com-

pounds, such as amino acids, the magnitude of optical rotation is a function of the degree of ionization up to a constant and limiting value. For example, the behavior of the ionic



FIG. 1. Behavior of Specific Rotation of L-Glutamic Acid. 
form of L-glutamic acid dependent on $\mathrm{pH}$ is shown in Fig. 1. This phenomenon is called Lutz-Jirgenson's rule, namely, (a) the optical rotation is given minimum value in neutral aqueous soultion, (b) the value increases to the positive side by an addition of acid or alkali and, (c) the optical rotation reaches a constant value independent on addition of acid or alkali, if such additions exceed that necessary to form a single ionic form.

In this study, experiments were carried out to determine whether this rule can be applied to all amino acids tested in the range from neutral to cationic form.

2. L-Aspartic Acid, L-Glutamic Acid and L-Glutamine

1) L-Aspartic Acid. Results are shown in Tables II-1 and II-2. The latin square was

TABLE II-I. RESULTS OF L-ASPARTIC ACID

\begin{tabular}{cccccc}
$\begin{array}{c}\text { Concentra- } \\
\text { tion of } \\
\text { the solute }\end{array}$ & \multicolumn{5}{c}{ Normality of hydrochloric acid } \\
$2 \mathrm{~N}$ & $2 \mathrm{~N}$ & $4 \mathrm{~N}$ & $5 \mathrm{~N}$ & $6 \mathrm{~N}$ \\
4 & $25.10^{\circ}$ & $25.28^{\circ}$ & $25.04^{\circ}$ & $24.58^{\circ}$ & $23.28^{\circ}$ \\
6 & 25.30 & 25.67 & 25.24 & 25.03 & 24.28 \\
8 & 24.96 & 25.74 & 25.51 & 25.39 & 24.90 \\
10 & 25.26 & 26.13 & 25.83 & 25.51 & 25.28 \\
& 25.33 & 26.18 & 26.10 & 25.70 & 25.46
\end{tabular}

TABLE II-2. ANALYSIS OF VARIANCE

\begin{tabular}{crrrll} 
Factors & \multicolumn{1}{c}{$\mathrm{S}$} & $\phi$ & $\mathrm{V}$ & \multicolumn{1}{c}{$\mathrm{F}_{\mathbf{0}}$} & \multicolumn{1}{c}{$\mathrm{F}$} \\
$\mathrm{A}$ & 37959 & 4 & 9489.3 & $9.81 * *$ & $\phi 1=4$ \\
B & 37453 & 4 & 9336.3 & $9.65 * *$ & $\phi 2=12$ \\
D & 3901 & 4 & 975.3 & 1.01 & 5.41 \\
E & 11604 & 12 & 967.0 & & \\
T & 90917 & 24 & & &
\end{tabular}

** Effective difference with $99 \%$ probability designed to investigate the effect of various factors, namely, A: solute concentration, B: hydrochloric acid concentration, $D$ : vessels (measuring flask $(100 \mathrm{ml})$ ). As will be seen from Table III-2, the effect on specific rotation due to solute and solvent concentration is within 99\% probability. The result is presented in Fig. 2. The concentration of solute increases the specific rotation linearly except in the case of $1 \mathrm{~N}$ hydrochloric acid. The increasing rate of the specific rotation in a

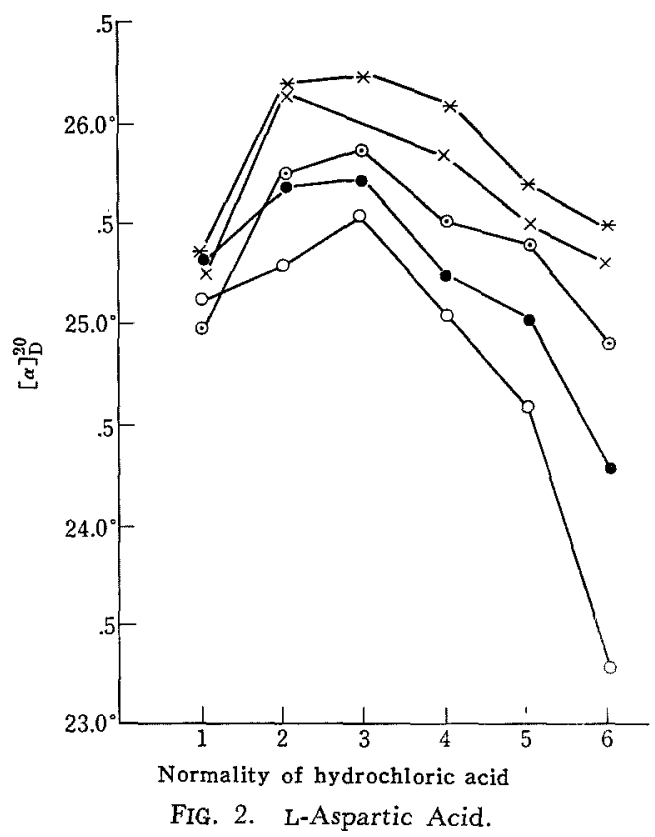

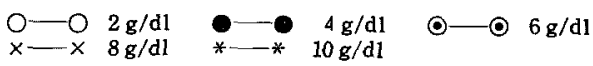

TABLE III. InCEasing Rate of Optical Rotation to Concentration OF THE AMINo ACIDS $\Delta[\alpha]_{\mathrm{D}}^{20} / \Delta \mathrm{C}$

\begin{tabular}{lcccccccc}
\multicolumn{8}{c}{ Amino acids } & \multicolumn{7}{c}{ Normality of hydrochloric acid } \\
& 0.5 & 1 & 2 & 3 & 4 & 5 & 6 & Mean \\
L-Aspartic acid & - & - & 0.11 & - & 0.13 & 0.14 & 0.27 & - \\
L-Alanine & - & - & 0.04 & - & 0.04 & 0.07 & 0.08 & - \\
L-Isoleucine & - & 0.13 & 0.10 & - & 0.15 & 0.14 & 0.18 & 0.14 \\
L-Leucine & - & 0.14 & 0.09 & - & 0.16 & 0.18 & 0.19 & 0.17 \\
L-Methionine & - & 0.16 & 0.13 & - & 0.15 & 0.15 & 0.15 & 0.15 \\
L-Valine & - & - & 0.12 & - & 0.04 & 0.13 & 0.12 & 0.12
\end{tabular}


TABLE IV. INCREASING Rate OF the Optical Rotation to ConCentration OF HYDROCHLORIC ACID $\Delta[\alpha]_{0}^{20} / \mathrm{HCl}-\mathrm{N}$

$\quad$ Amino acids
L-Arginine HCl
L-Leuine
L-Tyrosine
L-Valine

\begin{tabular}{|c|c|c|c|c|c|c|c|c|c|}
\hline \multicolumn{9}{|c|}{ Concentration of the solute $(\mathrm{g} / \mathrm{dl})$} & \multirow{2}{*}{ Mean } \\
\hline T & 2 & 4 & 5 & 6 & 7 & 8 & 10 & 12 & \\
\hline - & - & 0.31 & - & 0.28 & - & 0.28 & - & 0.34 & 0.30 \\
\hline 0.65 & 0.49 & 0.66 & - & 0.59 & - & 0.07 & - & - & 0.62 \\
\hline-0.24 & -0.44 & - & -0.77 & 一 & -0.67 & - & - & - & - \\
\hline- & 0.66 & 0.77 & - & 0.69 & 一 & 0.76 & 0.81 & - & 0.74 \\
\hline
\end{tabular}

concentration of solute between $2 \mathrm{~g} / \mathrm{dl}$ and $10 \mathrm{~g} / \mathrm{dl}$ in each concentration of hydrochloric acid is shown in Table IV. The rotation of L-aspartic acid has a maximum value in the range of $2 \sim 3 \mathrm{~N}$ hydrochloric acid under any solute concentration. The rotation does not reach maximum value at a $1: 1$ ratio of inorganic acid to amino acid.

2) L-Glutamic Acid. L-Glutamic acid is very slightly soluble in highly concentrated hydrochloric acid, so that experiment is carried out in a limited range, for example, as shown in Fig. 3. Although L-glutamic acid has almost constant value on the cationic side $\left([\alpha]_{D}^{20}=\right.$ $\left.+32.0^{\circ}\right),{ }^{5 \prime}$ as hydrochloric acid is further added, the specific rotation decreases slowly L-aspartic acid.

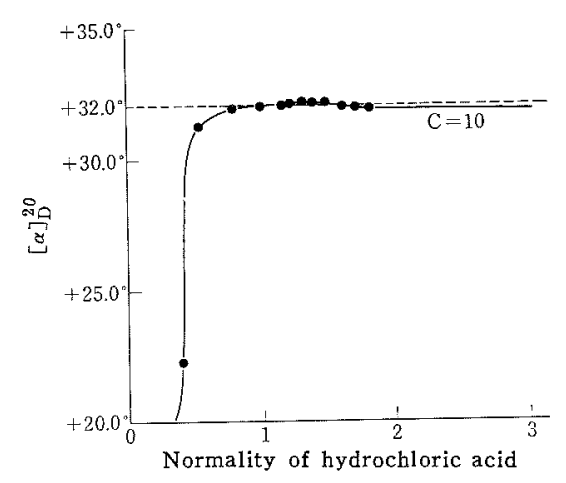

FIG. 3. L-Glutamic Acid.

3) L-Glutamine. The studies were carried out in water and hydrochloric acid. Solubility of L-glutamine in water is small, for instance, $4.2 \mathrm{~g}$ per $100 \mathrm{~g}$ water at $25^{\circ} \mathrm{C}$, so that optical rotation was measured only at the concentra-

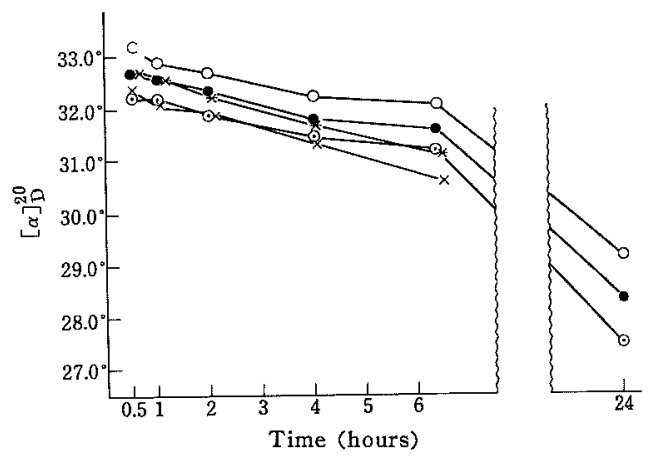

FIG. 4. L-Glutamine, Change of Optical Rotation with Time.

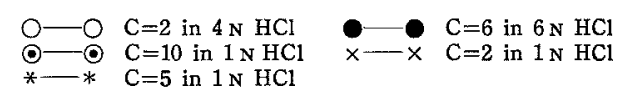

tion of $4 \%$.

The specific rotation, $[\alpha]_{\mathrm{D}}^{20}$, was $+6.5^{\circ}$

It was observed that the optical rotation decreased with storage period in hydrochloric acid solution of various solute concentration (Fig. 4). This result showed L-glutamine was unstable in hydrochloric acid solution, and measurement of the optical rotation as indication of the purity is unsuitable in cationic side.

\section{L-Alanine}

The results are shown in Fig. 5. Hydrochloric acid is present at more than $1: 1$ molar ratio to L-alanine, so L-alanine is considered as being in cationic form except at 10 to $12 \mathrm{~g} / \mathrm{dl}$ concentration of L-alanine $1_{\mathrm{N}}$ of hydrochloric acid. This optical rotation rises steeply with increases in concentration. This result is similar to that of M.S. Dunn et al. ${ }^{6)}$ Increasing rate of the optical rotation to solute concen- 




FIG. 5. L-Alanine.

$\mathrm{O}-\mathrm{O} 2 \mathrm{~g} / \mathrm{dl}$

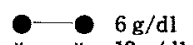

$\bigcirc-\circ 8 \mathrm{~g} / \mathrm{dl}$

tration is described in Table III.

The rate is higher in high hydrochloric acid concentration than that in diluted solutions. The optical rotation declines, as the inorganic acid concentration becomes progressively higher.

\section{4) L-Arginine Monohydrochloride}

The results are shown in Fig. 6. Effect of $\mathrm{L}$-arginine concentration of the optical rotaion is very small. The value rised linearly with increasing concentration of hydrochloric acid, and the increasing rate of the optical rotation value to hydrochloric acid concentration is about 0.30 as shown in Table IV. This result is consistent with that of by H. K. Miller.

\section{L-Citrulline}

The results are shown in Fig. 7.

Effect of the solute concentration is small. The value rises up linearly with increase in

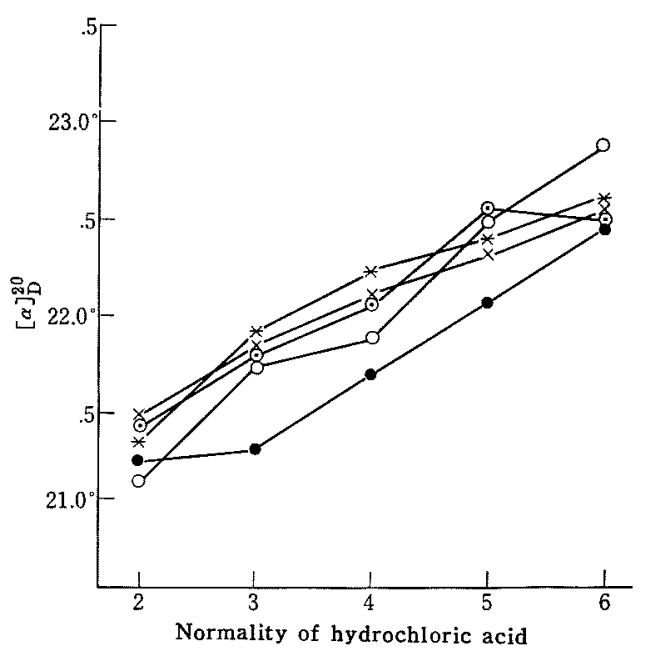

FIG. 6. L-Arginine $\mathrm{HCl}$.
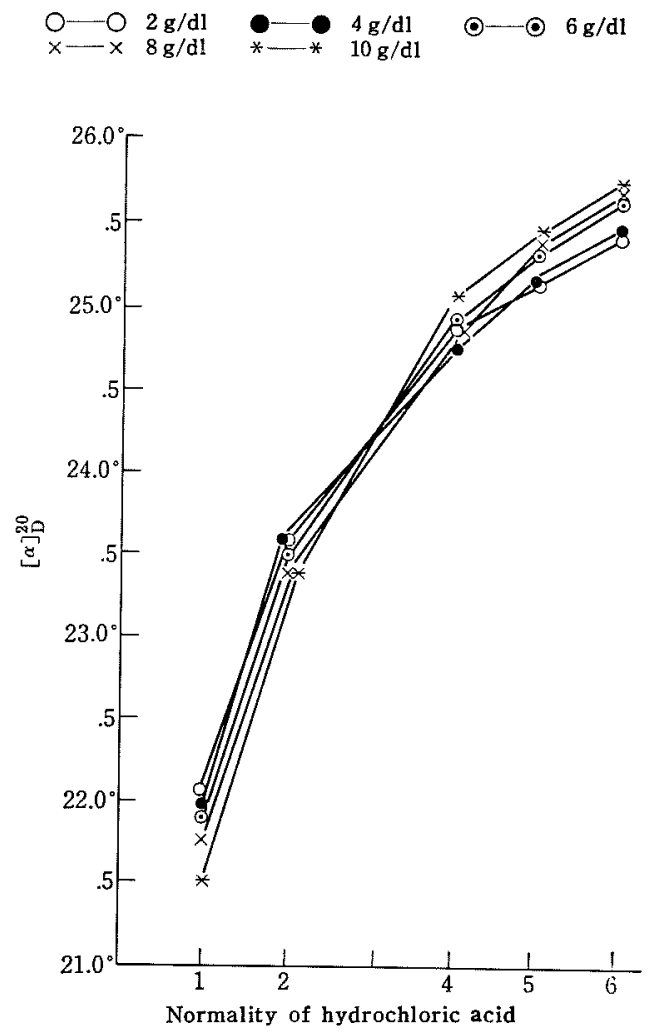

FIG. 7. L-Citrulline.




concentration of hydrochloric acid.

\section{L-Cystine}

The optical rotation decreased in proportion to concentration of the solute and hydrochloric acid. The results are shown in Fig. 8.

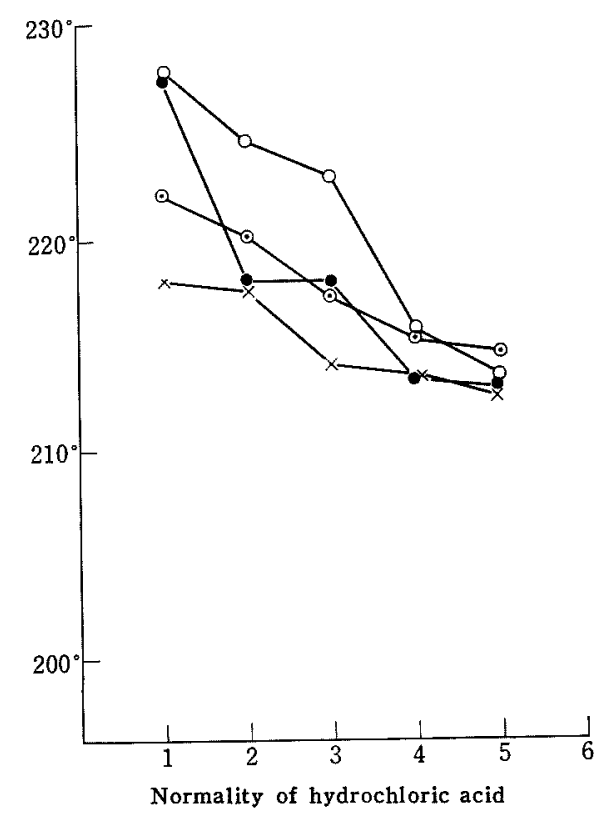

FIG. 8. L-Cystine.

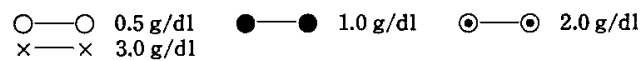

\section{L-Histidine Monohydrochloride Monohydrate}

The results are illustrated in Fig. 9. Hydrochloric acid is present at more than $1: 1$ to L-histidine $\mathrm{HCl} \cdot \mathrm{H}_{2} \mathrm{O}$. The specific rotation decreases little by little as the concentration of $\mathrm{L}$-histidine $\mathrm{HCl} \cdot \mathrm{H}_{2} \mathrm{O}$ increases. It is interesting that contrary to this case the value of other amino acids increase slowly with increasing concentration of the solute.

The value rises with increase in concentration of hydrochloric acid within lower range and reaches constant value at 4 to $6 \mathrm{~N}$ of the hydrochloric acid. This result is contrary to that of M.S. Dunn ${ }^{8 /}$ in which is described that concentration of sample does not have

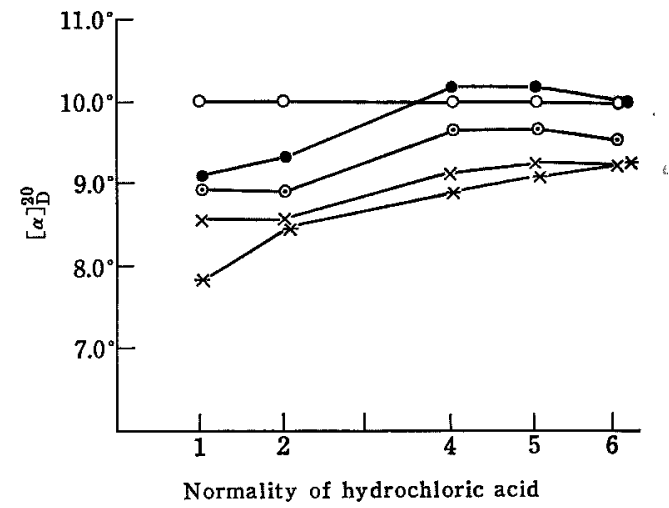

FIG. 9. L-Histidine $\mathrm{HCl} \cdot \mathrm{H}_{2} \mathrm{O}$.

$$
\begin{array}{ll}
O-O & \mathrm{C}=1 \\
\mathrm{x}-\mathrm{C}=11
\end{array} \stackrel{*-*}{\mathrm{C}=} \begin{aligned}
& \mathrm{C}=4 \\
& \mathrm{C}=15
\end{aligned} \quad \bigcirc-\bigcirc \mathrm{C}=7
$$

any effect on the value.

\section{L-Hiydroxyproline}

The results are shown in Fig. 10. The optical rotation is not effected by concentration of the solute in the case of water, but it mostly decreases in proportion to concentration of hydrochloric acid.
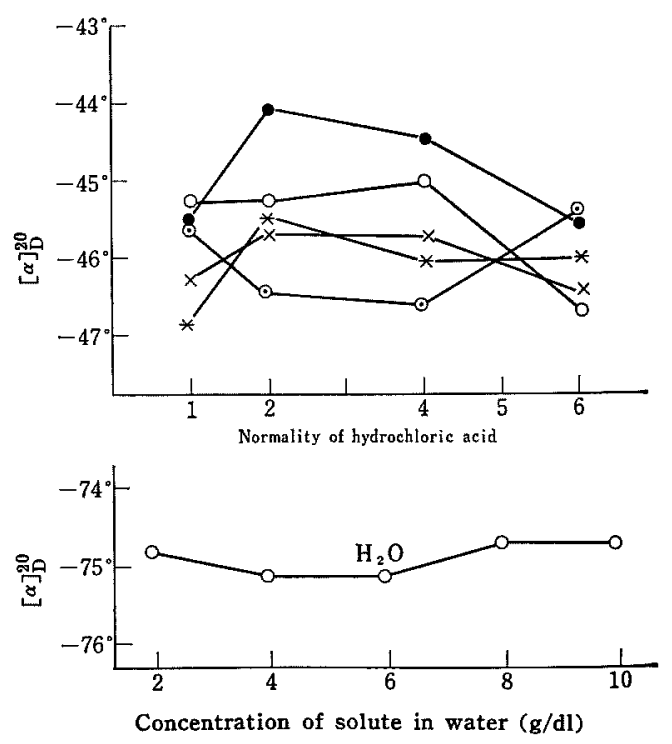

FIG. 10. L-Hydoxyproline.

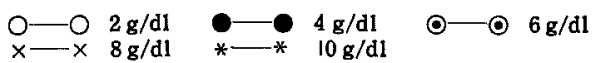




\section{L-Isoleucine}

The results are shown in Fig. 11. The specific rotation is raised linearly with rise in concentration of the solute. There is a highly significant difference with $99 \%$ probability of this occurrence by change alone. The increasing rate of the value to the solute concentration is about 0.14 as shown in Table IV. The optical rotation also increases with concentration of hydrochloric acid (a highly significant difference with $99 \%$ probability). The study

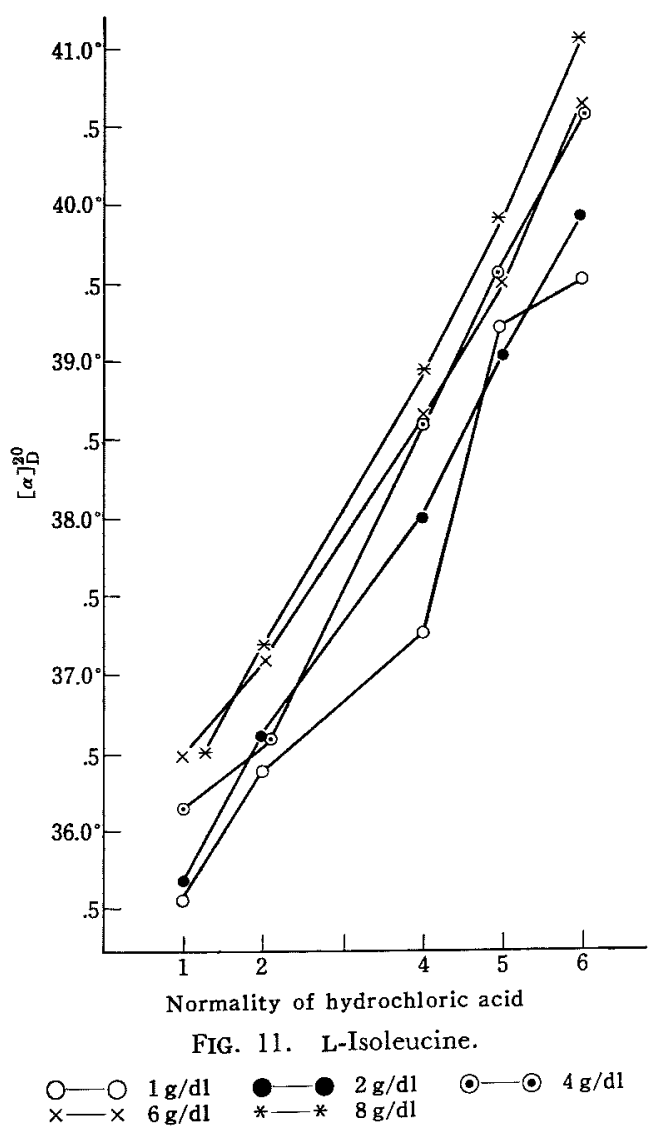

TABLE V. SPECIFIC Rotation OF L-Isolucine

Concentration

Normality of hydrochloric acid

of the solute

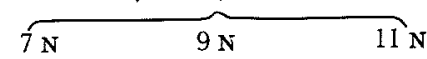

$1 \mathrm{~g} / \mathrm{dl}$

$41.34^{\circ}$

$42.38^{\circ}$

8

41.86

43.18

$43.85^{\circ}$

44.29 was further carried out in connection with concentrations of 7,9 and $11 \mathrm{~N}$ hydroloric acid, and result is shown in Table V. It is recognized from Table VI that the rate of increase of the value is in the same trend as Fig. 11. The increasing rate of the optical rotation to concentration of hydrochloric acid is found as 0.84 by calculation. This value corresponds to more than $2 \%$ of the rotation of L-isoleucine $\left([\alpha]_{\mathrm{D}}^{20}=+40^{\circ}\right)$, so it is necessary to keep the concentration of hydrochloric acid rigidly controlled.

From this point of view, it is preferable to measure the optical rotation in as high a concentration of hydrochloric acid as possible, but a concentration more than $6 \mathrm{~N}$ hydrochloric acid is rarely ever used as a practical solvent.

\section{L-Leucine}

The results are illustrated in Fig. 12. In-

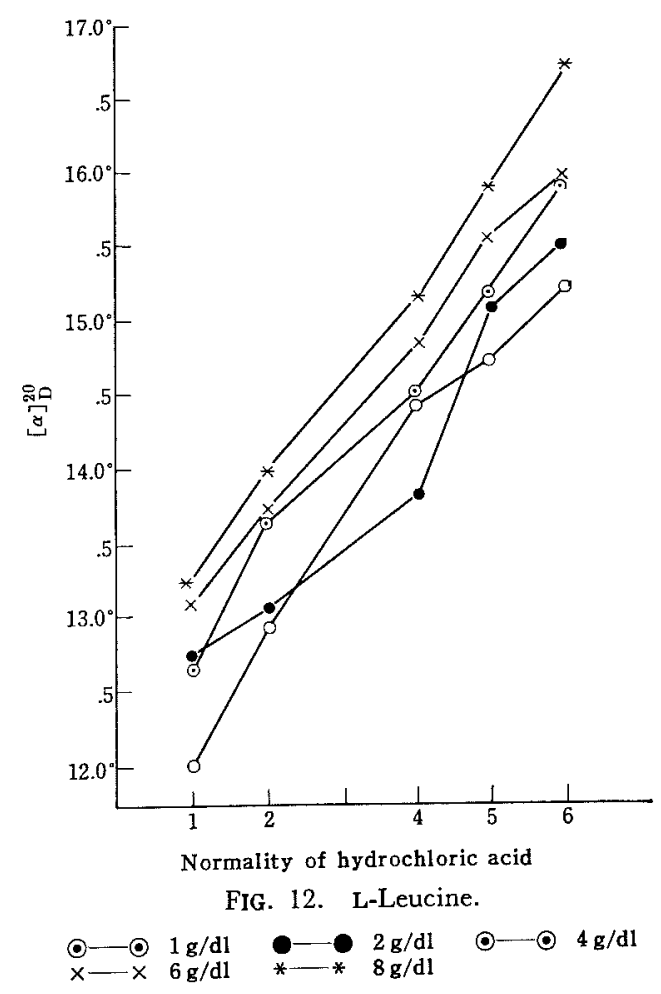


creasing the concentration of the solute effects a linear rise in the optical rotation and the increasing rate is shown in Table III. The increasing rate $(=0.17)$ resembled that of $\mathrm{L}$ isoleucine $(0.14)$, and the relative value to the empirical specific rotation of $\mathrm{L}$-leucine $\left(+15^{\circ}\right)$ is higher than in L-isoleucine. With increasing concentration of hydrochloric acid, the optical value steeply rises.

The work of D.W. Thomas et al. ${ }^{9 !}$ shows the concentration of L-leucine gives little effect on $[\alpha]_{\mathrm{D}}^{20}$ in the range of $2 \mathrm{~g} / \mathrm{dl}$ to $5 \mathrm{~g} / \mathrm{dl}$ with $6.02 \mathrm{~N}$ hydrochloric acid. But these results do not agree with ours (Table IV).

11. L-Lysine Monohydrochloride

The results are illustrated in Fig. 13. The

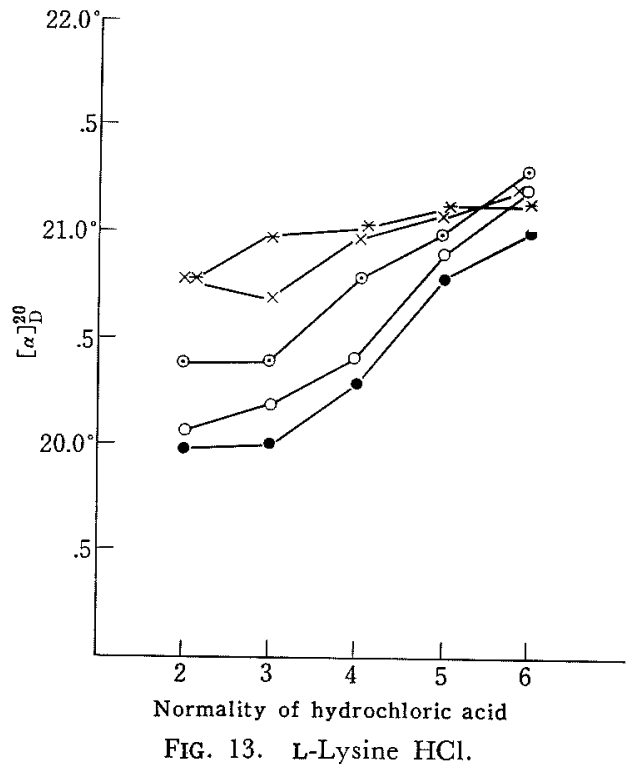

$\mathrm{O}-\mathrm{O} \quad 2 \mathrm{~g} / \mathrm{dl}$

\begin{tabular}{ll}
$*-1$ \\
$*-*$ & $\mathrm{~g} / \mathrm{d} 1$ \\
\hline$-\mathrm{gl}$
\end{tabular}

(-) $6 \mathrm{~g} / \mathrm{dl}$

value are raised by increasing the concentration of hydrochloric acid and the solute, and reach almost constant value at $6 \mathrm{~N}$ hydrochloric acid.

\section{L-Methionine}

The results are described in Fig. 14. In-

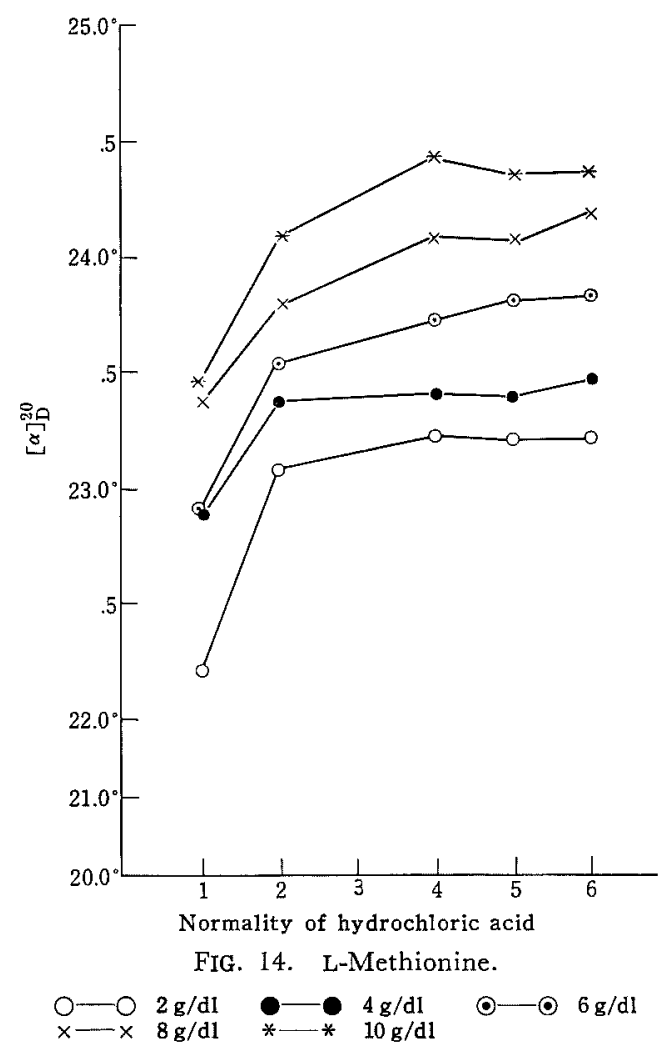

creases in concentration of the solute raise the optical rotation linearly. There is a very significant difference in $99 \%$ probability, and it is very interesting that the increasing rate of optical rotation to the solute concentration is almost constantly independent on concentration of hydrochloric acid shown in Table III.

L-Methionine is the only amino acid to which Lutz and Jirgenson's rule can be strictly applicable. The specific rotation increases in 1 to $2 \mathrm{~N}$ hydrochloric acid and reaches at constant value in 4 to $6 \mathrm{~N}$ hydrochloric acid. This result agrees well with that by J.R. Spies. ${ }^{101}$

\section{L-Phenylalanine}

The results are illustrated in Fig. 15. The concentration of the solute gives little effect 


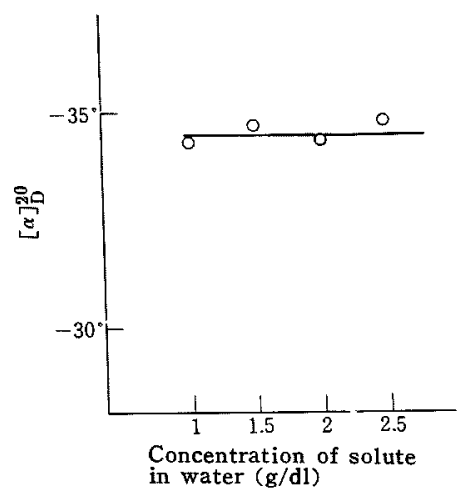

FIG. 15. L-Phenylalanine.

to the specific rotation.

\section{L-Proline}

The results are shown in Fig. 16. The
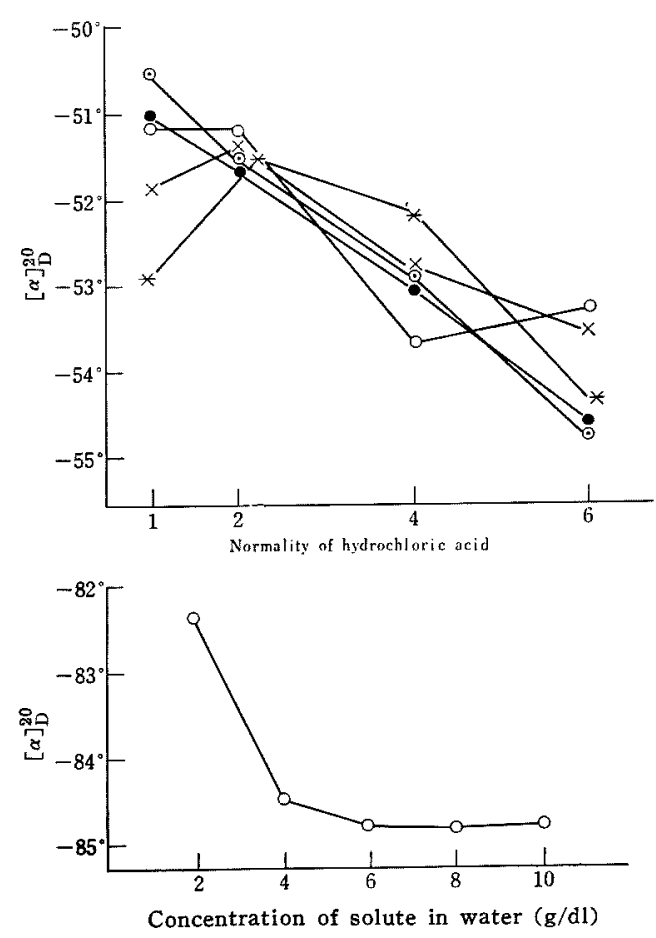

FIG. 16. L-Proline.



specific rotation inceases in the range of concentration of 2 to $4 \mathrm{~g} / \mathrm{dl}$ and reaches at constant value at a concentration of 4 to $10 \mathrm{~g} / \mathrm{dl}$ of the solute when water is used as sovlent. The concentration of the solute gives little effect to the rotation, as hydrochloric acid is used. The optical rotation in solute concentrations up to $10 \mathrm{~g} / \mathrm{dl}$ in $1 \mathrm{~N}$ hydrochloric acid shows extremely low value, as free amino acid is still present in this condition. The increase of concentration of hydrochloric acid causes a linear decrease of the optical rotation and the decreasing rate is about 0.6.

\section{L-Serine}

The results are shown in Fig. 17. The increase of concentration of hydrochloric acid causes a decrease of the optical rotation.

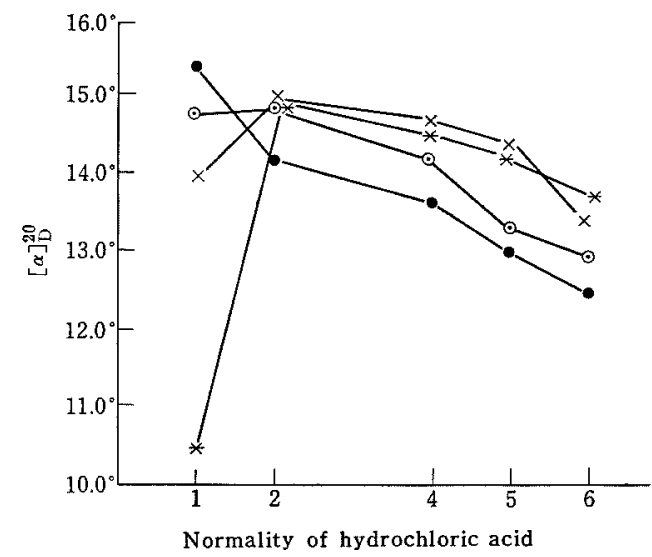

FIG. 17. L-Serine.

$$
\underset{*-\infty}{-} 5 \mathrm{~g} / \mathrm{dl} / \mathrm{g} / \mathrm{d} 1
$$

\section{L-Threonine}

The results are shown in Fig. 18. The concentration of the solute gives little effect to the specific rotation, when water is used as solvent. But increases of concentration of $\mathrm{L}$-threonine have effects to decrease the specific rotation. 


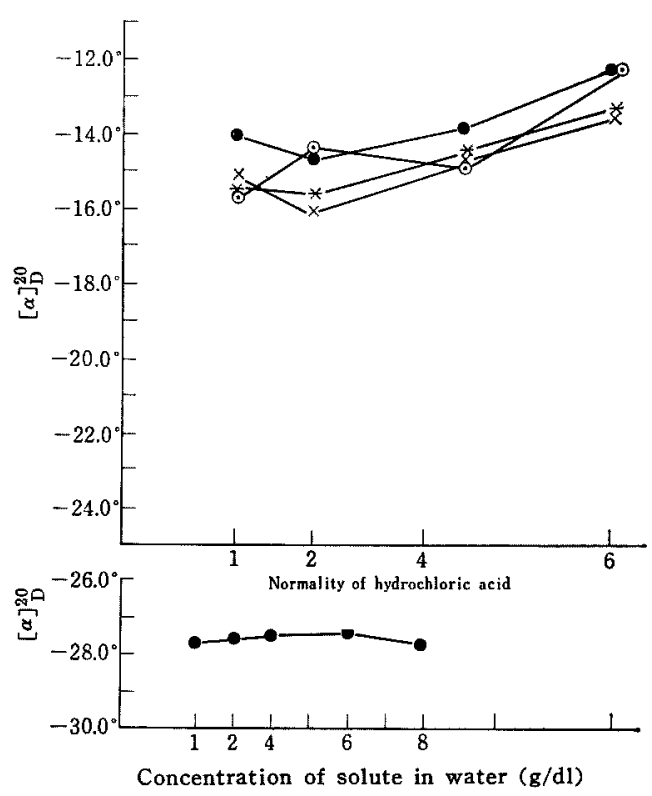

FIG. 18. L-Threonine.

$\underset{*-*}{2} \underset{8 \mathrm{~g} / \mathrm{dl}}{\longrightarrow} \odot-\odot 4 \mathrm{~g} / \mathrm{dl} \quad \times-\times 6 \mathrm{~g} / \mathrm{dl}$

\section{L-Tryptophan}

The results are shown in Fig. 19. The concentration of the solute gives little effect to the specific rotation.

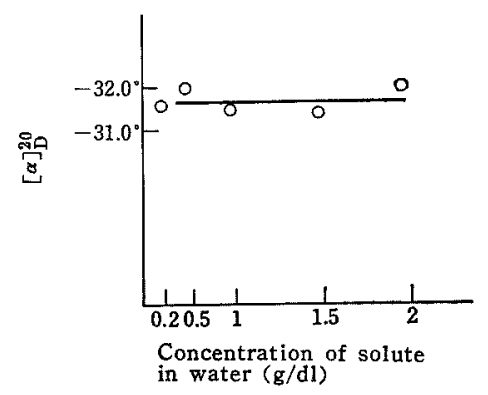

FIG. 19. L-Tryptophan.

\section{L-Tyrosine}

The optical rotation increases in proportion to concentration of the solute in hydrochloric acid of low concentration and becomes a constant value at high concentration of hydro-

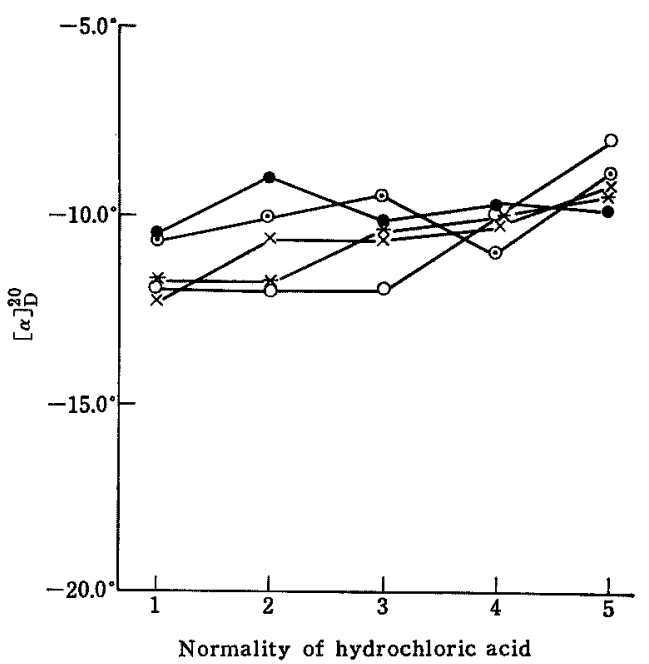

FIG. 20. L-Tyrosine.
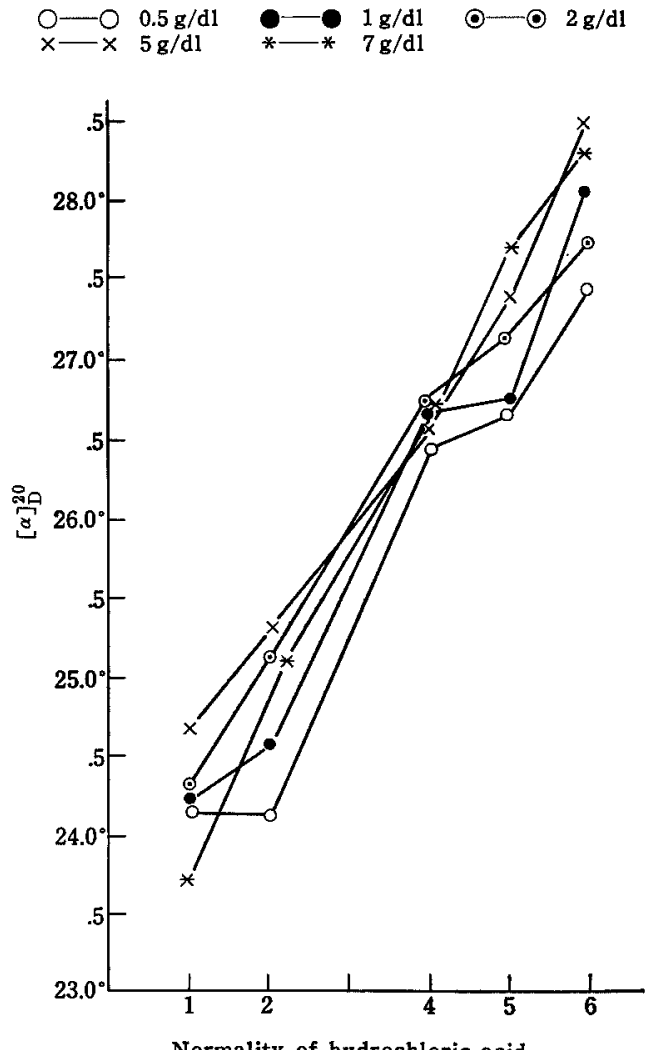

Normality of hydrochloric acid FIG. 21. L-Valine.

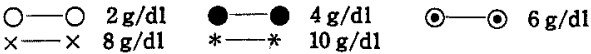


chloric acid. The concentration of the solute adds to the optical rotation (decrease of absolute value)except in the $0.5 \mathrm{~g} / \mathrm{dl}$ of L-tyrosine, and the increasing rate is illustrated Table IV

The rate inclines to increase in proportion to the concentration of the solute. The optical concentration in determining the optical rotation is that of $5 \mathrm{~g} / \mathrm{dl} \mathrm{L}$-tyrosine in $1 \mathrm{~N}$ hydrochloric acid, as rotation shows the maximum value under the experimental conditions (Fig. 20).

\section{L-Valine}

The results are shown in Fig. 21. Increases of concentration of L-valine have effects to raise the optical rotation, but the increasing rate is not so large as seen in the following (Table III).

The optical rotation increases linearly upon adding hydrochloric acid to the solution, and the value further rises in high concentration of hydrochloric acid. It is considered that the low value in $10 \mathrm{~g} / \mathrm{dl}$ in $1 \mathrm{~N}$ hydrochloric acid is due to the presence of free valine. The incereasing rate of the optical rotation to concentration of hydrochloric acid is illustrated in Table IV and the relative value to the specific rotation is about $2.7 \%$.

20. Specification and criteria for biochemical compounds by National Academy of ScienceNational Research Council (NAS-NRC) ${ }^{11}$.

The results of these studies, were compared with the specification described of NRC in 1960 , and these specific rotation and condition of measurement for almost all amino acids agree well with "NAS-NRC," but the determination by NRG with three amino acids

TABle VI. Comparison to NAS-NRC



11) Official Specification for Amino Acids.

(1) NAS-NRC (National Academy of Science* National Research Council, U.S., 1960)

(2) JIS (Japanese Industrial Standards).

\begin{tabular}{|c|c|c|}
\hline $\begin{array}{l}\text { Concentration of } \\
\text { solute and solvent }\end{array}$ & $\begin{array}{l}\text { Specific } \\
\text { rotation } \\
{[\alpha \alpha]_{D}^{20}}\end{array}$ & $\begin{array}{l}\text { Reading and } \\
\text { remark }\end{array}$ \\
\hline $\mathrm{C}=1 ; 6 \mathrm{~N} \mathrm{HCl}$ & $\left(\mathrm{t}=25^{\circ} \mathrm{C}\right)$ & $\begin{array}{l}\alpha=0.19^{\circ} \\
\text { Relative error } \\
\quad: 5.2 \%\end{array}$ \\
\hline $\begin{array}{l}\mathrm{C}=11 ; 6 \mathrm{~N} \mathrm{HCl} \\
\mathrm{HCl}(1+1)\end{array}$ & $9.3^{\circ}$ & $\begin{array}{l}2.0^{\circ} \\
\text { Relative error } \\
: 0.5 \%\end{array}$ \\
\hline $\mathrm{C}=10 ; 6 \mathrm{~N} \mathrm{HCl}$ & $9.3^{\circ}$ & $\begin{array}{l}\alpha=1.9^{\circ} \\
\text { Relative error } \\
\quad: 0.5 \%\end{array}$ \\
\hline $\mathrm{C}=0.8 ; 0.2 \mathrm{~N} \mathrm{HCl}$ & $21.1^{\circ}$ & $\begin{array}{c}\alpha=0.34^{\circ} \\
\text { Relative error } \\
\quad: 2.9 \%\end{array}$ \\
\hline $\mathrm{C}=8 ; 6 \mathrm{~N} \mathrm{HCl}$ & $23.3^{\circ}$ & $\begin{array}{c}\alpha=3.7^{\circ} \\
\text { Relative error } \\
: 0.3 \%\end{array}$ \\
\hline $\mathrm{C}=8 ; 4$ to $6 \mathrm{~N} \mathrm{HCl}$ & $24.0^{\circ}$ & $\begin{array}{c}\alpha=3.8^{\circ} \\
\text { Relative error } \\
: 0.3 \%\end{array}$ \\
\hline $\mathrm{C}=2 ; 5 \mathrm{~N} \mathrm{HCl}$ & $-10.0^{\circ}$ & $\begin{array}{c}\alpha=0.4^{\circ} \\
\text { Relative error } \\
: 2.5 \%\end{array}$ \\
\hline $\begin{array}{l}\mathrm{C}=4.8 ; 1 \mathrm{~N} \mathrm{HCl} \\
\mathrm{HCl}(1+1)\end{array}$ & $-11.6^{\circ}$ & $\begin{array}{c}\alpha=1.1{ }^{\circ} \\
\text { Relative error } \\
: 0.9 \%\end{array}$ \\
\hline $\mathrm{C}=5 ; 1 \mathrm{~N} \mathrm{HCl}$ & $120^{\circ}$ & $\begin{array}{l}\alpha=1.2^{\circ} \\
\text { Relative error } \\
\quad: 0.8 \%\end{array}$ \\
\hline $\begin{array}{l}\text { (3) The Japanese Phar } \\
\text { (4) The United States } \\
\text { (5) The National Form } \\
\text { (6) The Japanese Stan }\end{array}$ & $\begin{array}{l}\text { opoeia VII. } \\
\text { rmacopoeia } \\
\text { y, U.S. XI. } \\
s \text { of Food A }\end{array}$ & $\begin{array}{l}(1960) . \\
\text { ives (1960). }\end{array}$ \\
\hline
\end{tabular}


(whose rotation are very small) is made with error of measurement over $\pm 2 \%$ of the allowance of NRG. Namely, in L-histidine $\mathrm{HCl}$.

Table VII. The Optimal Condition OF MEASUREMENT

\begin{tabular}{|c|c|c|c|}
\hline Amino acids & $\begin{array}{l}\text { Concen- } \\
\text { tration } \\
\text { of the } \\
\text { solute* }\end{array}$ & Solvent & $\begin{array}{c}\text { Specific } \\
\text { rotation } \\
{[\alpha]_{D}^{20}}\end{array}$ \\
\hline \multirow[t]{2}{*}{ L-Alanine } & $\mathrm{C}=10$ & $6 \mathrm{~N} \mathrm{HCl}$ & $+14.7^{\circ}$ \\
\hline & $\mathrm{C}=10$ & $2 \mathrm{~N} \mathrm{HCl}$ & +15.5 \\
\hline L-Arginine $\mathrm{HCl}$ & $\mathrm{C}=8$ & $6 \mathrm{~N} \mathrm{HCl}$ & +22.5 \\
\hline L-Aspartic acid & $\mathrm{C}=10$ & 2 to $3 \mathrm{~N} \mathrm{HCl}$ & +26.2 \\
\hline L-Citrulline & $\mathrm{C}=8$ & $6 \mathrm{~N} \mathrm{HCl}$ & +25.8 \\
\hline L-Cystine & $\mathrm{C}=2$ & $1 \mathrm{~N} \mathrm{HCl}$ & +22.3 \\
\hline L-Glutamic acid & $\mathrm{C}=10$ & $2 \mathrm{~N} \mathrm{HCl}$ & +32.0 \\
\hline L-Glutamine & $\mathrm{C}=4$ & Water & +6.5 \\
\hline $\begin{array}{l}\text { L-Histidine } \\
\mathrm{HCl} \cdot \mathrm{H}_{2} \mathrm{O}\end{array}$ & $\mathrm{C}=10$ & $6 \mathrm{~N} \mathrm{HCl}$ & +9.3 \\
\hline L-Hydroxyproline & $\mathrm{C}=4$ & Water & -75.1 \\
\hline L-Isoleucine & $C=4$ & $6 \mathrm{~N} \mathrm{HCI}$ & +40.7 \\
\hline L-Leucine & $C=4$ & $6 \mathrm{~N} \mathrm{HCI}$ & +15.1 \\
\hline L-Lysine $\mathrm{HCl}$ & $\mathrm{C}=8$ & $6 \mathrm{~N} \mathrm{HCl}$ & +21.2 \\
\hline L-Methionine & $C=8$ & 4 to $6 \mathrm{~N} \mathrm{HCl}$ & +24.2 \\
\hline L-Phenylalanine & $\mathrm{C}=2$ & Water & -34.3 \\
\hline L-Proline & $C=4$ & Water & -84.8 \\
\hline L-Serine & $C=10$ & $2 \mathrm{~N} \mathrm{HCl}$ & +15.0 \\
\hline L-Threonine & $\mathrm{C}=6$ & Water & -28.5 \\
\hline L-Tryptophan & $\mathrm{C}=1$ & Water & -31.5 \\
\hline L-Tyrosine & $\mathrm{C}=5$ & $1 \mathrm{~N} \mathrm{HCl}$ & -12.0 \\
\hline L-Valine & $C=8$ & $6 \mathrm{~N} \mathrm{HCl}$ & +28.0 \\
\hline
\end{tabular}

$\mathrm{H}_{2} \mathrm{O}$ the reading of the rotation is about +0.19 in concentration of $1 \mathrm{~g} / \mathrm{dl}$ and measurement error is considered as $\pm 0.01^{\circ}$, therefore the relative error becomes more than $5 \%$. This relative error is over $2 \%$ of the allowance. In L-methionine, L-histidine as well, the rotation is very small owing to low concentration of the solute and hydrochloric acid is not sufficient to assure that the amino acid present is a single species.

A constant value can be obtained in the excess hydrochloric acid solution as described before. As for the third amino acid, L-tyrosine, the rotation is small, so measurement error is so large and over the $2 \%$ allowance (Table VI).

In conclusion, the general inclination of optical rotation to increase of concentration of the solute and solvent were summarized in Table VIII, and the optical condition of measurement for 20 amino acids were recommended in Table VII on these studies.

Acknowledgement. The authors wish to thank Y. Kawamura, Superintendent, and K. Yoshimura, Manager, Amino Acid Dept. of Ajinomoto for their helpful suggestions and encouragement. The authors are also indebted to Professor Dr. K. Shimura for valuable advice and checking reference. 